\title{
Sediment Sources Analysis Using CSSI Method in Pasir Buncir Micro-watershed, Bogor, Indonesia
}

\author{
B. Aliyanta* and P. Sidauruk \\ Center for Isotopes and Radiation Application, National Nuclear Energy Agency, \\ Jl. Lebak Bulus Raya No. 49, Jakarta 12070, Indonesia
}

\section{ARTICLE INFO}

Article history:

Received 25 September 2017

Received in revised form 8 October 2018

Accepted 10 January 2019

\section{Keywords:}

Sediment sources

Streambed sediment

CSSI

Land use

Micro-watershed

Soil organic carbon

\begin{abstract}
A B S T R A C T
There is an increasing need for reliable information concerning the source of the suspended sediment transported by rivers. Such information is required both to design effective sediment and non-point pollution control strategies and to provide an improved understanding of erosion and suspended sediment transport within a watershed. In some situations, there are many developing methods of fingerprinting to determine the contribution of sediment sources via the streambed sediment. In this study, compound-specific stable isotope (CSSI) fingerprint has been used to determine sediment source contribution in Pasir Buncir micro-watershed, Bogor, West Java. CSSI method is a newly developed technique in sediment sources contribution determination. This new technique is considered to be a very accurate technique for identifying the sediment sources contribution, especially in a watershed that has relatively similar soil types. This technique has been applied to studying the sediment source contribution study in a watershed with three different land uses with mostly clay loam soil type. One sample from each of three different land uses was collected vertically from the $0-2 \mathrm{~cm}$ depth range. Streambed sediment from the nearest outlet from the micro-watershed was also collected. Soil and streambed sediment samples were analyzed for $\delta^{13} C$ of bulk organic carbon and CSSI contents. The $\delta^{13} C$ of bulk organic carbon and CSSI contents analysis showed that all the three different land uses (one-season crop, intercropping, and pine forest) contributed to streambed sediment; approximately $79.2 \%$ was from cultivated land of one-season crop, $15.2 \%$ from intercropping land, and $5.6 \%$ from pine forest.
\end{abstract}

(C) 2019 Atom Indonesia. All rights reserved

\section{INTRODUCTION}

Sediment source contribution information is very important for sustainable watershed management implementation. Sediment source contribution information can be used as starting point to develop sediment budget and land use management model in the watershed.

Sediment source contribution study involves several parameters such as land use, intensity and distribution of rain, soil type, and the variation of slopes of the watershed. The sediment source contribution study will be more complicated if the watershed has the same soil type. Several methods that are based on fingerprinting techniques have been developed [1]. These methods are alternative

* Corresponding author.

E-mail address: barali@batan.go.id

DOI: https://doi.org/10.17146/aij.2019.721 methods to identify sediment characteristics, and are able to estimate quantitative connection between sediment and its potential contributors. The fingerprinting technique can establish a direct quantitative relation between sediment and potential sources such as large-, small-, or micro-watersheds [2]. The relation between sediment source and sediment suspension is described using sediment source mixing model through mathematical and statistical analysis of hydrosedimentological properties of the watersheds [3-6].

Soil particles and sediment properties can be divided to three groups namely geochemical, biochemical, and physical properties [7]. Geochemical properties cover inorganic, radionuclide (i.e., ${ }^{7} \mathrm{Be},{ }^{10} \mathrm{Be},{ }^{137} \mathrm{Cs},{ }^{210} \mathrm{~Pb},{ }^{239} \mathrm{Pu}$, and ${ }^{240} \mathrm{Pu}$ ), and magnetic mineral properties. Most of developed fingerprint methods in sediment source contribution identification are based on geochemical 
properties of soil particles and sediments. Biochemical properties of soil particles and sediments cover organic materials (e.g., $\mathrm{C}, \mathrm{N}, \mathrm{P})$, biomarker (e.g., lignin, glucose, and acid fat), stable isotopes $\left(e . g ., \delta^{15} \mathrm{~N}, \delta^{13} \mathrm{C}\right)$, and organic chemicals (e.g., pesticides). These properties are used to relate downstream sediment with source contributors. Physical properties of soil particles and sediments covers particle size distribution, particle shape, and aggregation and disaggregation of particles. Studies on soil and sediments properties such as fingerprint techniques to identify erosion and sediment source identification have grown in the last decades. Currently, several researchers have given special attention to biochemical properties of soil particles and sediments especially biomarker and stable isotopes properties. The combination of biomarker and stable isotopes properties of soil particles and sediments is known as compound-specific stable isotopes (CSSI).

A general basic assumption in fingerprint techniques is that each potential sediment source site has distinct geochemical characteristics. Fallout radionuclide activity, one of geochemical characteristics, has been used in many studies such as determining the relative contribution of channel, gully, sheet, interrill, and rill erosions in an erosion process $[8,9]$. Fallout radionuclide activity has also been used to determine erosion relative contribution from different land uses [5]. Fallout radionuclide activity, along with $\mathrm{Na}, \mathrm{Mg}, \mathrm{Al}, \mathrm{Si}, \mathrm{P}, \mathrm{K}, \mathrm{Ca}, \mathrm{Ti}$, $\mathrm{Mn}$, and $\mathrm{Fe}$ chemical content analyses, has successfully identified bacterial bloom process in lakes [10]. Physical properties of soil particles and sediments have not been helpful in erosion and sediment source contribution studies.

Research activities on sediment dynamic in a watershed, using biochemical properties of soil particles and sediment, have grown very fast in the last few years. Biochemical properties of soil particles and sediment have been used to determine organic matter contribution in streambeds [11]; to determine sediment source contribution through long-chain n-alkane compound biomarker [12]; to reconstruct land use change process in watersheds through the age and n-alkane sediment [13]; and to identify onshore sediment source through stable isotope $\left(\delta^{13} C\right)$ analysis [14].

The application of CSSI as a main tracer in sediment fingerprint study has grown in Europe, North America, South America, and East Asia regions. This technique has not been used widely in South East Asia region due to the lack of isotope ratio mass spectrometry-gas chromatography (IRMS-GC) facilities. In Indonesia, this technique was adopted through Indonesian participation in regional projects sponsored by the International Atomic Energy Agency (IAEA) such as regional project RAS 5055 and regional project RAS 5069.

In CSSI technique, the relative content of ${ }^{13} \mathrm{C}$ $\left(\delta^{13} C\right)$ of bulk soil as well as streambed sediment is assumed as a representation of the $\delta^{13} C$ of the straight-chain fatty acid of its main composer [15]. This technique measures $\delta^{13} C$ of saturated fatty acid at each potential sediment source and at the streambed sediment within watershed with a relatively homogeneous soil type. By this technique, the contribution of each land use to the total sediment bed can be apportioned.

A fatty acid is an organic acid that occurs in a natural triglyceride and is a monocarboxylic acid with 4 to 28 carbon atoms in straight chains and usually has either a saturated hydrocarbon chain or one to six double bonds. Saturated fatty acids are long-chain carboxylic acids that usually have 12 to 24 carbon atoms and have no double bonds. Thus, saturated fatty acids are saturated with hydrogen. Most saturated fatty acids are straight hydrocarbon chains with an even number of carbon atoms [16]. It is probably safe to say that saturated fatty acids in nature are not susceptible to biological degradation, and they can be considered as a conservative tracer.

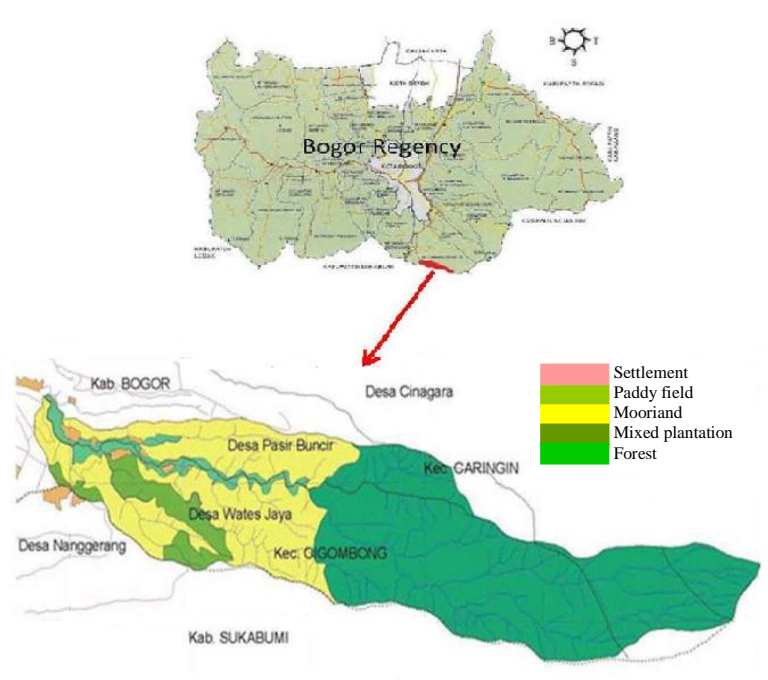

Fig. 1. The location of the study.

\section{METHODOLOGY}

\section{Location of the study}

The location of the study was in Pasir Buncir micro-watershed, Bogor, West Java. Pasir Buncir is a small part of the upstream of Cisadane River watershed and it is depicted in Fig. 1. The microwatershed stretches from $106^{\circ} 49^{\prime} 48^{\prime \prime}$ to 
$106^{\circ} 55^{\prime} 48^{\prime}$ ' East and from $6^{\circ} 45^{\prime} 36^{\prime}$ ' to $6^{\circ} 47^{\prime} 24$ ' South, with a total area of about 1770 hectares [17].

Based on soil map produced by Indonesian Soil and Agro-climate Research Center, the soil in the study area is dominated by andosols group that covers almost $92 \%$ of the area and cambisols group that covers less than $8 \%$ of the area. Andosols develop from volcanic origin such as volcanic ash and they are known for their fertility and high porosity. Because of their high porosity, andosols have a high capability to convey water; hence, in general, they are not very sensitive to erosion.

Based on the data collected from the nearest agro-climate station, namely the Pasir Jaya station, about $3 \mathrm{~km}$ away from the study location, the average annual rainfall is about $3256 \mathrm{~mm}$ with almost even distribution. Rain falls in about nine months each year (September to May). Land uses inside the study area is given in Table 1 . This land use data is very important for sediment sources determination.

Table 1. Land uses in Pasir Buncir micro-watershed.

\begin{tabular}{llll}
\hline \multirow{2}{*}{ No } & \multirow{2}{*}{ Land uses } & \multicolumn{2}{c}{ Area } \\
\cline { 3 - 4 } & & hectare & $\%$ \\
\hline 1 & Settlement & 12.1 & 0.68 \\
2 & Paddy field & 73.5 & 4.15 \\
3 & Moorland & 546.1 & 30.85 \\
4 & Mixed plantation & 108.9 & 6.15 \\
5 & Forestry & 1029.4 & 58.16 \\
\hline \multicolumn{2}{c}{ Total } & 1770.0 & 100.0 \\
\hline
\end{tabular}

\section{Sampling procedures}

Soil samples were collected in transects from all different land uses such as moorland, mixed plantation, and pine forest. In general, the slope of the site exceeds $30^{\circ}$ (Fig. 2). Soil sample was collected from 0 to $2 \mathrm{~cm}$ depth using a corer with a diameter of about $10 \mathrm{~cm}$. Soil and sediment suspension samples were used to evaluate the source of sediment within Pasir Buncir micro-watershed. There were ten soil and sediment suspension samples that were collected from all different land uses and outlets within the micro-watershed. Because the samples would be analyzed for its CSSI contents, they were collected with extra care to prevent any external contamination such as from human sweat [15]. Before sampling, unpowdered nitrile gloves were put on to avoid contamination from hands. Each soil sample had to be mixed well before putting in in a ziploc bag. Before the ziploc bag was sealed, air was expelled from the bag as much as possible by rolling the plastic ziploc bag. The sampling points and their corresponding coordinates are given in Table 2.
Table 2. Altitude and coordinate of sampling points.

\begin{tabular}{|c|c|c|c|c|}
\hline \multirow{2}{*}{ No. } & \multirow{2}{*}{ Sediment source } & \multicolumn{2}{|c|}{ Coordinate } & \multirow{2}{*}{$\begin{array}{l}\text { Altitude } \\
\text { (asl, m) }\end{array}$} \\
\hline & & South & East & \\
\hline 1 & Seasonal crop A & $06^{\circ} 45^{\prime} 39^{\prime \prime}$ & $106^{\circ} 50^{\prime} 01.3^{\prime \prime}$ & 598 \\
\hline 2 & Intercropping & $06^{\circ} 45^{\prime} 44^{\prime \prime}$ & $106^{\circ} 50^{\prime} 36^{\prime \prime}$ & 608 \\
\hline 3 & Pine forestry & $06^{\circ} 45^{\prime} 44.6$ & '106 $50^{\circ}$ ' 38.4" & 623 \\
\hline 4 & Seasonal crop B & $06^{\circ} 45^{\prime} 56.7$ & '106 $50^{\circ} 02.5^{\prime \prime}$ & 651 \\
\hline 5 & Streambed sediment & $06^{\circ} 45^{\prime} 26.8$ & '106'49'42.4" & 549 \\
\hline
\end{tabular}

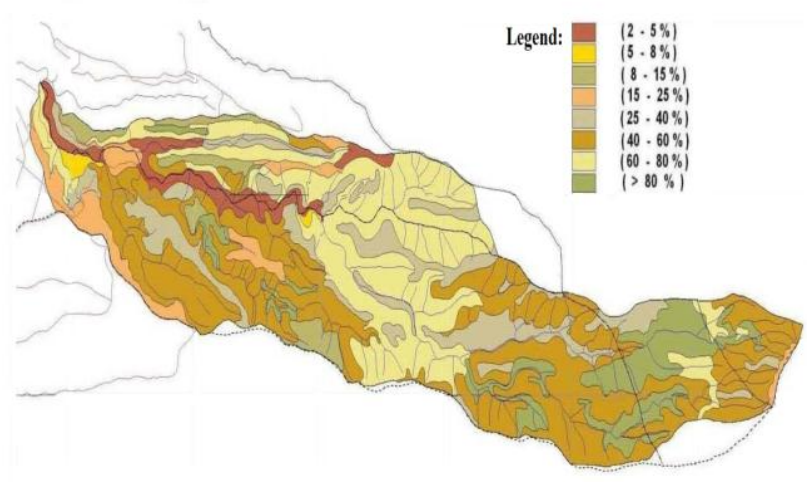

Fig. 2. Slopes of study area site.

\section{Preparation of samples for CSSI analysis}

Soil and sediment suspension samples were prepared at the Industrial and Environment Laboratory, Center for Isotopes and Radiation Application. This preparation was intended to determine the total organic material (TOM) content in the soil samples. All samples were dried in an oven at a temperature of $40{ }^{\circ} \mathrm{C}$ for 2 or 3 days. All collected samples were sieved such that only particles finer than $1 \mathrm{~mm}$ would be retained. The retained samples $(\sim 0.7-1 \mathrm{~kg})$ were separated into two parts in which one part was for CSSI content analysis and the other part was for percentage of total organic matter content determination. For total organic matter determination, the samples were first dried in a furnace with a temperature about $105{ }^{\circ} \mathrm{C}$ then let them to cool down before being weighted and reheated [15]. For CSSI analysis, on the other hand, the samples were heated at $40{ }^{\circ} \mathrm{C}$ in an oven, and about 75 grams of each sample was wrapped in a plastic and alumunium foil package. Then, the prepared samples were sent to China Academy of Agricultural and Soil (CAAS) for CSSI analysis using gas chromatograph-isotope ratio mass spectrometer (GC-IRMS).

\section{Derivatization}

Fatty acid in soil is an organic acid in natural triglycerides and it is a monocarboxylic acid with atomic bond chain from $\mathrm{C} 4$ to $\mathrm{C} 28$ or more 
and normally has a saturated hidrocarbon chain. The fatty acid in soil originates from decayed organic matter and plants, microbial activities, and interaction of plants with fungi. Fatty acids exhibit a polarity that will tend to cause them bind into ionic surfaces such as soil surface. In addition, fatty acids will bind materials in gas chromatography columns.

To overcome this unwanted behavior, fatty acids were substituted by methyl groups $\left(\mathrm{CH}_{3}\right)$ through a process called derivatization or methylation [12]. Derivatization and methylation processes are processes to convert natural fatty acids into another compound that can be analyzed using gas chromatography. The first step is called derivatization process that is to change the carboxyl groups of fatty acids to their ester groups. The second step is called methylation process that is to change fatty acids ester into fatty acid methyl ester by adding methyl groups and the produce fatty acid methyl ester (FAME). FAME has higher vortality and more stable [18].

\section{Measurement of saturated fatty acid (FA)}

While the FAME was derived from fatty acid through methylation process, the isotope ratio $\delta^{13} C$ of FAM differed from fatty acids (FA). The relation of the $\delta^{13} C$ of FA and FAME is given in eq. (1).

$$
\delta^{1} C_{F A}=\frac{\delta^{13} C_{F A M E}-(1-x) \delta^{13} C_{\text {Methanol }}}{x}
$$

In (1), $x$ is the proportion of FA in FAME, and it is obtained from the total carbon of FA divided by the total carbon of FAME. The total carbon in added methyl in FAME is relatively very small; hence, $x$ is generally close to 1 .

\section{RESULTS AND DISCUSSION}

\section{$\delta^{13} \mathrm{C}$ of bulk soil dan total organic material}

The relative isotope content $\left(\delta^{13} C\right)$ of bulk soil is calculated using eq. (2),

$$
\delta^{13} C=\frac{R_{\text {soil }}-R_{\text {std }}}{R_{\text {std }}} \times 1000(\%)
$$

In (2), $R_{\text {soil }}$ and $R_{\text {std }}$ represent carbon isotope ratios ${ }^{13} \mathrm{C} /{ }^{12} \mathrm{C}$ of soil sample and standard, respectively. The international standard for carbon is based on the $\mathrm{CO}_{2}$ obtained from a Cretaceous belemnite which is called V-PDB (Vienna-Pee De Belemnite) standard.

The $\delta^{13} C$ of bulk soil, total organic material, and carbon contents for the four different land uses and streambed sediment are given in Table 3. It can be seen from Table 3 that $\delta^{13} C$ values of bulk soil range from $-42.85 \%$ to $-21.76 \%$. The highest value is in the pine forest, and the lowest one is in cultivated with one-season crop land use. The relative total organic material $(\% \mathrm{C})$ of soil ranges from 14.81 to $17.66 \%$. The highest percentage is in the pine forest and the lowest one is in cultivated-with-one-season-crop land use. These phenomena are caused by canopy layer factor [19]. The percentage of ground surface shaded by the leaves or branches in the pine forest is obviously higher than that in other land uses. Pine forests absorbs more carbon than other land uses that makes the $\delta^{13} C$ of pine forest will be more enriched (higher) than in other land uses. The observed $\delta^{13} C$ of bulk streambed sediment is within the $\delta^{13} C$ value range of the four different land uses; this indicates that the four land uses contributed to the streambed sediment. Total organic material conversion in percentage of soil organic carbon $(\% \mathrm{C})$ was taken to be 0.47 from total organic material [15].

Table 3. $\delta^{13} C$ values, total organic material (TOM), and carbon contents $(\% \mathrm{C})$ in soil and streambed.

\begin{tabular}{lccc}
\hline $\begin{array}{l}\text { Land uses/streambed } \\
\text { sediment }\end{array}$ & $\begin{array}{c}\boldsymbol{\delta}^{\mathbf{1 3}} \boldsymbol{C}_{\text {bulk }} \\
(\mathbf{\%})\end{array}$ & $\begin{array}{c}\text { TOM } \\
(\mathbf{\%})\end{array}$ & $\begin{array}{c}\mathbf{C} \\
(\mathbf{\%})\end{array}$ \\
\hline $\begin{array}{l}\text { Cultivated A: one- } \\
\text { season crop }\end{array}$ & -42.85 & 14.81 & 6.96 \\
$\begin{array}{l}\text { Intercropping of cardamom } \\
\text { among wood plant }\end{array}$ & -26.49 & 17.06 & 8.02 \\
$\begin{array}{l}\text { Pine Forest } \\
\begin{array}{l}\text { Cultivated B: one-season } \\
\text { crop }\end{array}\end{array}$ & -21.76 & 17.66 & 8.30 \\
\begin{tabular}{l} 
Streambed sediment \\
\hline
\end{tabular} & -35.3 & 15.88 & 7.46 \\
\hline
\end{tabular}

Soil organic carbon is the carbon associated with organic matter. Soil organic matter is the organic fraction of the soil that is made up of decomposed plant and animal materials as well as microbial organism, but does not include fresh and undecomposed plant materials such as straw and litter lying on the soil surface. Moreover, soil carbon levels are determined by such factors as rainfall, temperature, vegetation, and soil type. In agricultural systems, soil carbon levels tend to vary and depend on management practices [20]. The change in soil organic carbon is determined by the balance of carbon inputs over losses. These phenomena were also observed in this area. Although cultivated land use A and B are both planted with one-season crop, they have significant differences in $\delta^{13} C, \% \mathrm{C}$, and TOM. This significant difference was caused by the fact that the oneseason crop in cultivated land A and land B were different, causing the capability of both cultivated land uses to absorb ${ }^{13} \mathrm{C}$ from the air differ. 
The higher the density of crops in the land, the more ${ }^{13} \mathrm{C}$ can be absorbed from the air during photosynthesis process. The capability of the crops/plants to absorb ${ }^{13} \mathrm{C}$ from the air during photosynthesis process will also affect the $\delta^{13} C$, $\% \mathrm{C}$, and total organic material in the soil. From Table 3, the linear regression line between $\delta^{13} C$ and $\% \mathrm{C}$ was developed with a correlation coefficient $\mathrm{R} \approx 1$ and the equation is $\delta^{13} C=15.71 \% \mathrm{C}-152.29$ as given in Fig. 3. This equation indicates that each one unit increase of carbon content in percent will increase the $\delta^{13} C$ by $15.71 \%$.

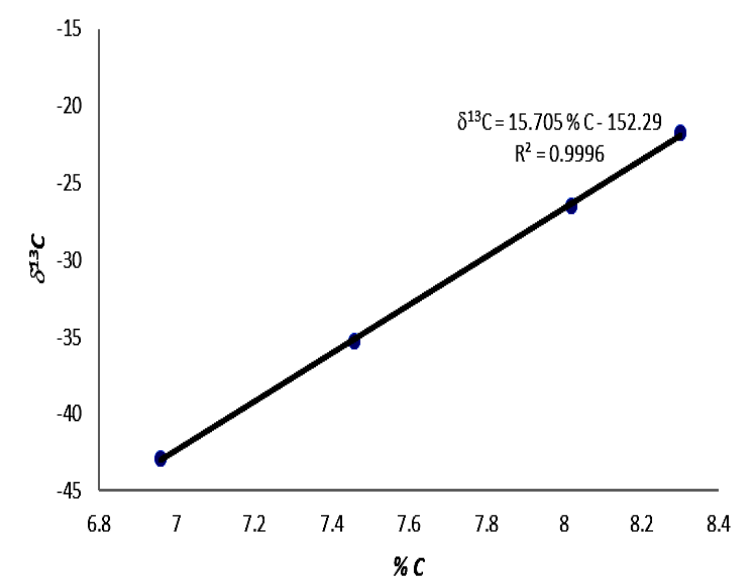

Fig. 3. The relation between $\delta^{13} C$ and $\% \mathrm{C}$.

\section{$\delta^{13} C$ of fatty acid in the sediment source and streambed sediment}

The $\delta^{13} C$ values of fatty acids from each land use were determined according to the number of saturated carbon bonds in FAME as appearing in gas chromatogram. The values of $\delta^{13} C$ of land uses (potential sediment sources) and streambed sediment for various carbon chains of the saturated fatty acids, such as myristic (C14), palmitic (C16), stearic (C18), arachidic (C20), behemic (C22), and lignoceric (C24), have been measured and listed in Table 4 [21]. As the $\delta^{13} C$ of lignoceric (C24) in the streambed sediment was not detectable and the $\delta^{13} C$ of behemic (C22) was significantly higher than those values from all other land uses, the $\delta^{13} C$ of both lignoceric and behemic are not listed in Table 4. From Table 4, $\delta^{13} C$ values of myristic (C14), palmitic (C16), stearic (C18), and arachidic (C20) fatty acids range from -33.56 to $-30.26 \%,-32.98$ to $-27.45 \%$, -29.23 to $-24.12 \%$, and -32.10 to $-27.74 \%$, respectively. This result agrees with the work by Zhu, et al., [14] in which they found that saturated fatty acid carbon chains in sediments were C12 to C32. The most significant of these carbon chains were C14, C16, C18, C20, C22, and C24.
In their study, however, the carbon chain of the saturated lignocerid fatty acid in sediment was not detected due to its very low concentration. As expected, Table 4 shows that the $\delta^{13} C$ values of streambed sediment are in the range of $\delta^{13} C$ values of all contributing sources. The fatty acid type is affected by the type of plants; hence, the fluctuations of $\delta^{13} C$ of $\mathrm{C} 14, \mathrm{C} 18, \mathrm{C} 20$, and $\mathrm{C} 22$ in Table 4 may be caused by farming or management practices and environmental factors such as canopy and altitude differences $[18,19]$.

Table 4. $\delta^{13} C$ values of saturated fatty acids of potential sediment sources and streambed sediment

\begin{tabular}{lcccc}
\hline Land use & $\begin{array}{c}\delta^{13} C_{\mathrm{C} 14} \\
(\%)\end{array}$ & $\begin{array}{c}\delta^{13} C_{\mathrm{C} 16} \\
(\%)\end{array}$ & $\begin{array}{c}\delta^{13} C_{\mathrm{C} 18} \\
(\%)\end{array}$ & $\begin{array}{c}\delta^{13} C_{\mathrm{C} 20} \\
(\% 0)\end{array}$ \\
\hline L-1 & -30.26 & -27.45 & -24.12 & -29.23 \\
L-2 & -32.19 & -29.94 & -29.80 & -31.93 \\
L-3 & -33.50 & -32.98 & -27.91 & -32.10 \\
L-4 & -31.38 & -32.68 & -28.27 & -29.95 \\
SBS & -33.56 & -28.27 & -29.23 & -27.74 \\
\hline
\end{tabular}

L-1: Cultivated A: one-season crop

L-2: Intercropping plants

L-3: Pine forest

L-4: Cultivated B: one-season crop

SBS: Streambed sediment

\section{Sediment contribution derived on the $\delta^{13} C$ fatty acids}

It has been stated in the previous discussion that $\delta^{13} C$ values of streambed sediment were normally in the range of $\delta^{13} C$ values of all contributing sources. The contributing sources in this case are all the four land uses. The contribution of each land use to the streambed sediment were determined from eqs. (3) and (4):

$$
\begin{gathered}
\delta^{13} C_{F-S B S}=c_{1} \delta^{13} C_{F L U-1}+c_{2} \delta^{13} C_{F L U-2}+ \\
c_{3} \delta^{13} C_{F L U-3}+c_{4} \delta^{13} C_{F L U-4} \\
0 \leq c_{1}, c_{2}, c_{3}, c_{4} \leq 1 \\
\text { and } \quad c_{1}+c_{2}+c_{3}+c_{4}=1
\end{gathered}
$$

In eqs. (3) and (4), the symbols $\delta^{13} C_{F-S B S}, \delta^{13} C_{F L U-1}$, $\delta^{13} C_{F L U-2}, \delta^{13} C_{F L U-3}$, and $\delta^{13} C_{F L U-4}$ represent the $\delta^{13} C$ values of saturated fatty acid for streambed sediment, land use-1, land use-2, land use-3, and land use-4, respectively. On the other hand, $c_{1}, c_{2}$, $c_{3}$, and $c_{4}$ are the coefficients of contribution of saturated fatty acids of land use-1, land use-2, land use-3, and land use-4, respectively. Equation (3) has to be applied for all saturated fatty acids under 
consideration, namely myristic (C14), palmitic (C16), stearic (C18), and arachidic (C20) acids. Equation (3) cannot be solved analytically because of the constraint given in eq. (4). The solution of eq. (3) for all saturated fatty acids for the unknowns $c_{1}$, $c_{2}, c_{3}$, and $c_{4}$ will be found by minimizing the difference between the right-hand side and the left-hand sides. For this purpose, the relative squared error that is based on (3) for fatty acid $i$ is introduced in the following equation:

$$
\varepsilon_{i}=\left(\frac{y_{i}-\sum_{j=1}^{4}\left(c_{j} Y_{i, j}\right)}{y_{i}}\right)^{2}
$$

For simplification reason, new symbols have been introduced: $y_{i}$ is the $\delta^{13} C$ value of saturated fatty acid $i$ of streambed sediment, $Y_{i, j}$ is the $\delta^{13} C$ value of saturated fatty acid $i$ of land use $j$, and $c_{j}$ is the coefficient of contribution of land use $j$ for all $i=1$, $2,3,4$. Hence, the total error for all saturated fatty acids can be written as in (6):

$$
\varepsilon_{\text {total }}=\sum_{i=1}^{4}\left(\frac{y_{i}-\sum_{j=1}^{4}\left(c_{j} Y_{i, j}\right)}{y_{i}}\right)^{2}
$$

The coefficient of contribution of each land use $c_{j}$ $(j=1,2,3,4)$ will be determined by minimizing $(6)$ subject to (4). The minimization of the mixing model of (6) subject to (4) has been done using an available software package called IsoSource. IsoSource is a software package that can be used to calculate the contribution coefficient of each land use as a potential sediment sources to streambed sediment. The inputs that are required for this software package are: $1 . \delta^{13} C$ values of all saturated fatty acid from all land uses and streambed sediment; 2. proportion of contribution increment; and: 3. mass balance tolerance. On the other hand, the output of this software package is a set of descriptive statistics, i.e., mean, standard deviation, minimum, maximum, and the corresponding histograms of contribution coefficients of sources. In this study, all three sets of required inputs have been provided. The increment was set to $1 \%$ and the mass balance tolerance was set $2.5 \%$. The output is listed in Table 5 and the corresponding histograms was not shown for simplicity reason.
Table 5. Contribution of saturated fatty acids of sources to the fatty acid of sediment calculated by IsoSource software package.

\begin{tabular}{lc}
\hline Land uses/ Sediment sources & Contribution $(\%)$ \\
\hline Cultivated A: one-season crop & $36.5 \pm 4.1$ \\
Mixed plantation & $15.2 \pm 6.2$ \\
Pine forest & $5.6 \pm 4.5$ \\
Cultivated B: one-season crop & $42.7 \pm 7.5$ \\
\hline
\end{tabular}

From Table 5, it can be seen that the mean contribution coefficient of fatty acids from land uses to streambed fatty acid are $36.5,15.2,5.6$, and $42.7 \%$ for land use-1 (cultivated A: one-season crop), land use-2 (mixed plantation), land use-3 (pine forest), and land use-4 (cultivated B: oneseason crop), respectively. Based on these calculated contribution coefficients of fatty acids from land uses, the contribution coefficient of the soil from land uses were determined by considering the $\% \mathrm{C}$ of each land use as given in Table 3. The contribution coefficients of soil will be proportional to contribution coefficients of fatty acids divided by percentage of organic carbon and is given in Table 6.

\begin{tabular}{|c|c|c|c|c|}
\hline $\begin{array}{l}\text { Land } \\
\text { uses }\end{array}$ & $\% \mathrm{C}$ soil & $\begin{array}{l}C_{F A} \\
(\%)\end{array}$ & $\begin{array}{c}C= \\
\left(C_{F A} / \% C\right)\end{array}$ & $\begin{array}{l}C_{s} \\
(\%)\end{array}$ \\
\hline L-1 & 6.96 & 36.5 & 5.244 & 38.74 \\
\hline L-2 & 8.02 & 15.2 & 1.895 & 14.0 \\
\hline L-3 & 8.30 & 5.6 & 0.675 & 4.98 \\
\hline L-4 & 7.46 & 42.7 & 5.724 & 42.28 \\
\hline Total & & & $13.538(D)$ & 100 \\
\hline \multicolumn{5}{|c|}{$\begin{array}{l}\text { L-1: Cultivated A: one-season crop } \\
\text { L-2: Intercropping plants } \\
\text { L-3: Pine forest } \\
\text { L-4: Cultivated B: one-season crop } \\
C_{F A}: \text { Contribution coefficients of Fatty Acids } \\
D: \text { Total ratio of } \mathrm{C}_{\mathrm{FA}} \text { to } \% \mathrm{C} \text { for four land uses } \\
C_{s}: \text { Contribution coefficients of soil }=C / D \times 100\end{array}$} \\
\hline
\end{tabular}

Table 6. Streambed sediment source from soil of each land use.

It can be observed from Table 6 that the majority of streambed sediment (over $80 \%$ ) was contributed by cultivated land (A and $\mathrm{B}$ ), and the least contributor, as expected, was the pine forest $(4.98 \%)$. It is observed also from Table 6 that percentage of organic carbon $(\% \mathrm{C})$ has no apparent relation with sediment source contribution. This observation indicates that $\% \mathrm{C}$ alone cannot be used as a fingerprint for ascription of sediment sources.

\section{Validation of IsoSource package results using $\delta^{13} C$ bulk soil and sediment}

The consistency of contribution coefficient of sediment sources $\left(c_{1}, c_{2}, c_{3}\right.$, and $\left.c_{4}\right)$ calculated from IsoSource software package were crosschecked using measured $\delta^{13} C$ values of soil and streambed 
sediment. This step is very crucial and important to demonstrate the validity of the mixing model to represent current study. For this validation step, calculated contribution coefficients $\left(c_{1}, c_{2}, c_{3}\right.$, and $c_{4}$ ) were used to calculate the $\delta^{13} C$ value of bulk streambed sediment using eq. (7), which is a rewriting of (3):

$$
\begin{gathered}
\left(\delta^{13} C_{S B S}\right)_{c a l}=c_{1} \delta^{13} C_{L U-1}+c_{2} \delta^{13} C_{L U-2}+ \\
c_{3} \delta^{13} C_{L U-3}+c_{4} \delta^{13} C_{L U-4}
\end{gathered}
$$

In (7), $\left(\delta^{13} C_{S B S}\right)_{\text {cal }}$ is the calculated $\delta^{13} C$ values of bulk streambed sediment, and $\delta^{13} C_{L U-1}$, $\delta^{13} C_{L U-2}, \delta^{13} C_{L U-3}$, and $\delta^{13} C_{L U-4}$ are $\delta^{13} C$ values of bulk soil of land use-1, land use-2, land use-3, and land use-4, respectively.

Using the values given in Table 3 for $\delta^{13} C_{L U-1}$, $\delta^{13} C_{L U-2}, \delta^{13} C_{L U-3}, \quad \delta^{13} C_{L U-4}, \quad$ it was found that $\left(\delta^{13} C_{S B S}\right)_{\text {cal }}=-35.96 \%$. This calculated value is in a very close agreement with the measured value $\delta^{13} C_{S B S}=-35.8 \%$. This indicates that IsoSource mixing model represents the current study problems very well.

\section{CONCLUSION}

The results of relative organic carbon (\%), $\delta^{13} C$ of bulk soil, and $\delta^{13} C$ of long chain saturated fatty acid component analysis shows that the relative organic carbon $(\% \mathrm{C})$ is strongly proportional with the $\delta^{13} C$ of bulk soil. The $\delta^{13} C$ value of bulk soil of land use with better canopy layer indicate higher total organic carbon. The $\delta^{13} C$ values of saturated fatty acids (CSSI) of four different land uses have been shown to be a very effective means to determine the contribution of each land use to the sediment. The contribution of each land use was determined by means of statistical analysis through developed percent frequency versus contribution proportion graph. Based on this CSSI analysis, it is found that of the streambed sediment, approximately $79.2 \%$ is contributed by one-season crop land use, $15.2 \%$ by intercropping land use, and $5.6 \%$ by the pine forest.

\section{ACKNOWLEDGMENT}

The authors acknowledge that study was funded by the Government of Indonesia through BATAN Research Fund (DIPA) of year 2014. The authors also thank their laboratory assistants for providing them with the results of stable isotopes and chemical analysis of the samples. They also thank the Chinese Academy of Agricultural Sciences, Beijing, for performing the CSSI.

\section{REFERENCES}

1. C. Deasy and J.N. Quinton, Solid Earth 1 (2010) 111.

2. A. Haddadchi, D.S. Ryder, O. Evrard et al., Int. J. Sediment Res. 28 (2013) 560.

3. T. Tiecher, L. Caner, J.P.G. Minella et al., Soil Tillage Res. 155 (2016) 478.

4. H.G. Smith, G.J. Sheridan, P. Nyman et al., Geomorphology 139 (2012) 403.

5. B. Aliyanta, N. Suhartini and B. Pratikno, A Scientific Journal for the Applications of Isotopes and Radiation 11 (2015) 39. (in Indonesian)

6. M. Zebracki, F. Eyrolle-Boyer, O. Evrard et al., Sci. Total Environ. 502 (2015) 122.

7. A.J. Koiter, P.N. Owens, E.L. Petticrew et al., Earth-Science Rev. 125 (2013) 24.

8. P. Porto, D.E. Walling and A. Capra, Soil Tillage Res. 135 (2014) 18.

9. F.B. Zhang, M.Y. Yang, D.E. Walling et al., Geomorphology 206 (2014) 392.

10. J.S. Rowan, S. Black, S.W. Franks, Appl. Geogr. 32 (2012) 832.

11. R.J. Cooper, N. Pedentchouk, K.M. Hiscock et al., Sci. Total Environ. 520 (2015) 187.

12. F. Chen, N. Fang and Z. Shi, Sci. Total Environ. 557 (2016) 123.

13. Y. Wang, H. Yang, J. Zhang et al., Sci. Total Environ. 502 (2015) 266.

14. X. Zhu, S. Mao, N. Wu et al., J. Asian Earth Sci. 92 (2014) 262.

15. M. Gibbs, Protocols on the Use of the CSSI Technique to Identify and Apportion Soil Sources from Land Use, NIWA, Taihori Nukurangi, Hamilton, New Zealand (2014).

16. J. Salimon, T.A. Omar and N. Salih, Sci. World J. 2014 (2014) 1.

17. Anonymous, Integrated Cisadane River Watershed Management Year 2010, Final Report: Research Collaboration of Ministry of Forestry and Bogor Agriculture Institute, Ciliwung-Citarum Watershed Management Bureau, Bogor (2010) III-1. (in Indonesian)

18. D.G. Reiffarth, E.L. Petticrew, P.N. Owens et al., Sci. Total Environ. 565 (2016) 8.

19. S. Basu, S. Agrawal, P. Sanyal et al., Palaeogeogr. Palaeoclimatol. Palaeoecol. 440 (2015) 22.

20. K.R. Olson, Geoderma 195 (2013) 201.

21. A. Zielińska and I. Nowak, Chemik 68 (2014) 103. 